\title{
Intelligent evaluation in educational context
}

\author{
Riadh BESBES \\ Electrical department in national school of engineering \\ Research Group on Intelligent Machines \\ Sfax, Tunisia \\ Mohamed Moncef BENKHELIFA \\ Engineering laboratory for handicaps South university of \\ Toulon - Var, France
}

\author{
Adel M.ALIMI \\ Electrical department in national school of engineering \\ Research Group on Intelligent Machines \\ Sfax, Tunisia
}

\author{
Philippe GORCE \\ Engineering laboratory for handicaps
South university of Toulon - Var, France \\ Engineering laboratory for handicaps
South university of Toulon - Var, France
}

\begin{abstract}
The idea is to conceive an intelligent computing system of decision-making aid, in this context of teaching training, the quantification of the human behaviors is the key to this system's innovation. Seeing that it gives opportunity of measuring the professional acts of the teachers in class. This makes it possible to locate these practices compared to the pedagogical theories, into force and especially compared to the constructive approach. In addition, this system helps to identify the student's styles of learning; therefore it places, at the disposal, information which facilitates to the teachers the adaptation of their pedagogical methods so that the student benefit a maximum assimilation. For what concerns them, the students also profit from an innovating alternative: result of the web based performances analysis in summative evaluation. It is a generated report, for each pupil, automatically at the end of the seizure of the marks stipulating in details their weak points and specifying the adequate remedies in terms of activities to be realized to proceed to reflexive regulations in order to raise their levels of assimilation. An able system, starting from observable behaviors in classrooms and of performances seized remotely via the Web, to quantify in a rational way the cognitive and emotional states of the actors of the context of teaching training. An expert system whose general objectives would be: classifying the profiles of the teachers starting from their professional competences based on their pedagogy, behavior and attitude, classifying the learners' profiles by analyzing their interactions and analyzing their performances in summative evaluations, adapting the resources of the teacher's pedagogical methods in order to have a better coherence with the profiles of identities, the profiles of motivation and the profiles of comprehension of learner.
\end{abstract} profile

Keywords-component; Evaluation, statistics, learner profile, teacher

\section{INTRODUCTION}

The world in which we live witnesses the birth of expert systems which aim to classify and assist with the decision making whose complexity increases with the development of the tools, of the techniques related to decisional data processing. This observation is not limited to technical field but also related to the educational field and more precisely to the diagnosis and the evaluation of the process of teaching training. On the basis of a medical vision, the diagnosis is an activity of identification of the causes of a physical or human system's dysfunction starting from the observation of its revealing symptoms. Frequently, the dysfunctions are diagnosed starting from a whole of associated symptoms named characteristic syndrome. The relevance of the diagnosis is strongly dependant on the complete observability of the device.

We could, also, add that the etymology of the diagnosis term means "knowledge through signs". Therefore, a diagnosis of the profiles of the actors of teaching training can be interpreted as the knowledge of the cognitive state of the actor (teacher and/or learner) of the context through his actions and his reactions at the time of an activity of teaching training.

From there the idea to conceive an intelligent computing system of decision-making aid, in this context, which is a reliable tool in the hands of the secondary education's inspector. A system able to manage the variable characteristics of the learner and the teacher in order to facilitated a reliable decision making of what must be recommended for each whole of circumstances, thus avoiding the recourse to the intuition and subjective and nondescribable decision making in deterministic terms. An able system, starting from observable behaviors in classrooms and of performances seized remotely via the Web, to quantify in a rational way the cognitive and emotional states of the actors of the context of teaching training. An expert system whose general objectives would be: classify the profiles of the teachers starting from their professional competences based on their pedagogy, behavior and attitude. Classify the learners' profiles by analyzing their interactions and analyzing their performances in summative evaluations. Adapt the resources of the teacher's pedagogical methods in order to have a better coherence with the profiles of identities, the profiles of motivation and the profiles of comprehension of learner.

The organizational structure of this expert system is hybrid. Indeed, it is computer software installable on the laptop of the inspector and whose entries are seized, on the one hand, in class by the inspector. He interacts with the 
system using an interface man machine based on grids of teaching and didactic functions which we will detail later on. On the other hand, the marks of the students' summative evaluations are collected by the remote system starting from a Web site placed at the disposal of the students.

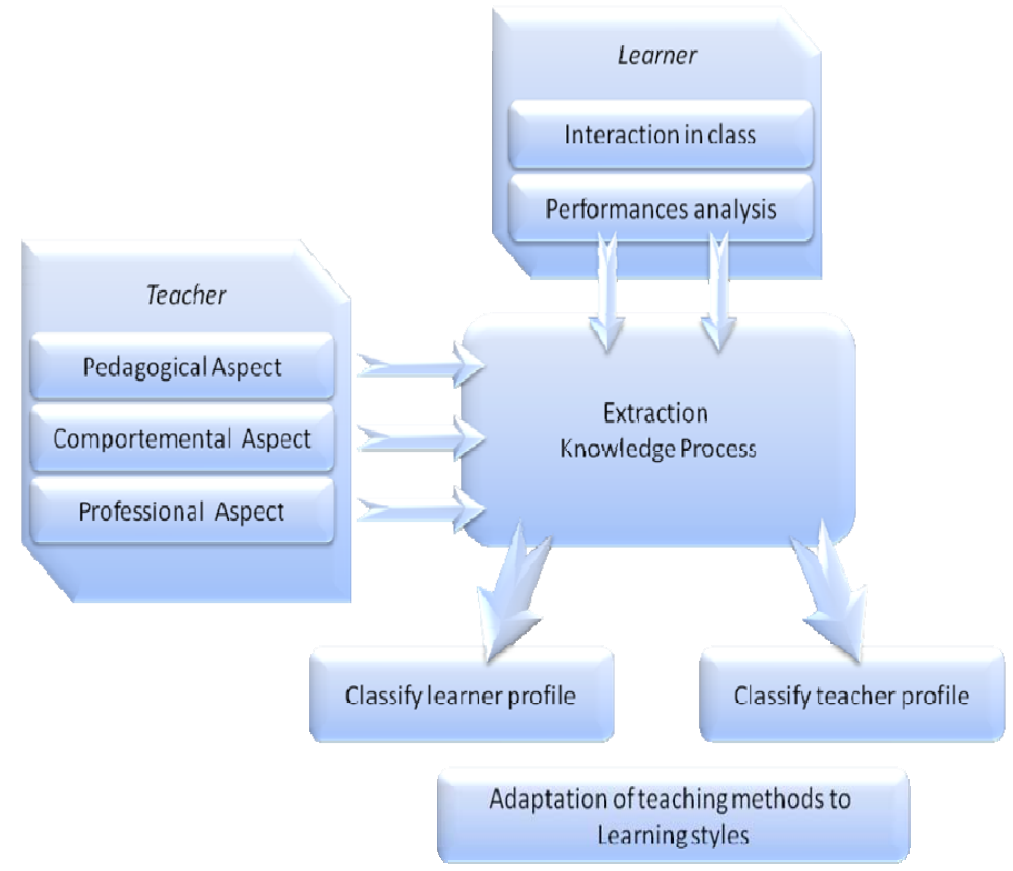

Figure 1

\section{DYNAMIC EDUCATIONAL PROCESS OF LEARNING} SEQUENCE

In trying to identify the key factors that characterize the various approaches that define the learning, we find that the role of students is essential. In constructing his knowledge that he built himself and who is constructing, acquiring knowledge. This interactive process of teaching and learning is modeled by Marcel Lebrun following five categories.

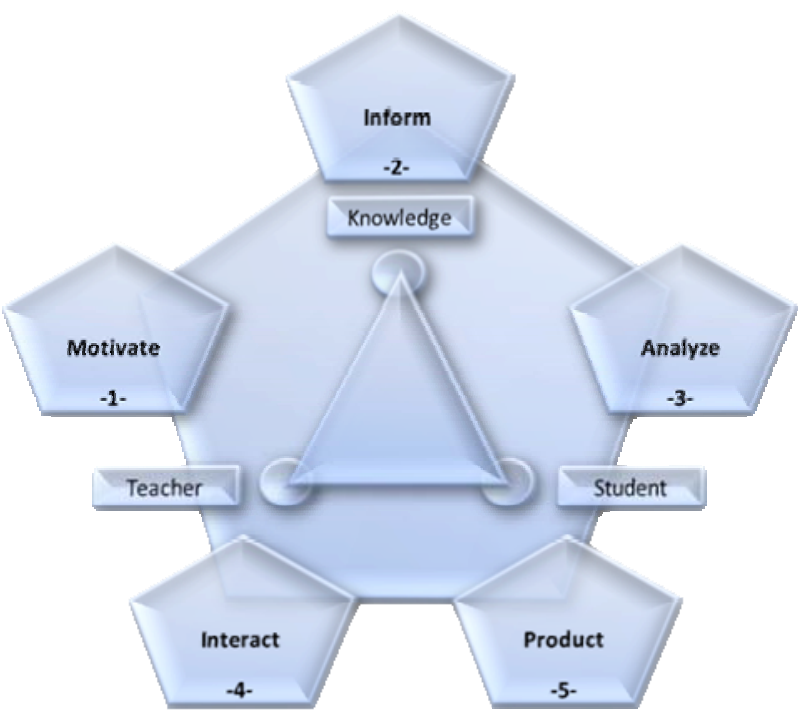

Figure 2

\section{A. The steps of a teaching learning sequence}

We began a sequence of teaching-learning by encountering a new situation, a problem suitable for students connected with circumstances known to them, so it presents a real opportunity to gauge their own prior knowledge and skills. And since meaning is given through structure, there is no shortage of ways to provide understanding of the structure to access the significance. This context would be motivating if it leads the student to give a value to the task, it is proposed by identifying the elements, facts, transactions that make sense and meaning. On the other hand, this context has an evocative power and potential for expansion because of its direct contact with reality, experience, applications, and needs: it causes management and control by the student.

The next step illustrates the importance of access and information gathering. Thus, we proceed to harvest information from the context, the views of students and their different representations, resource centers are meeting places, information is contextualized. This is mapping between world and formalism.

The analysis phase is gradually learning to learners to build tools for information retrieval, structuring, comparing, categorizing and confrontation. It means developing the ability to manipulate the world descriptions, relating and manipulating the various form of representation.

The stage of interaction operates the interactive and collaborative learning, emphasizes the importance of factors relating to communication and teamwork, and since action without feedback is unproductive for a learner, we use feedbacks intrinsic versus extrinsic or action in relation to representations, which allows the student to recognize his abilities.

Finally, the production stage that leads to reflection not confined to the goal but as aspect of the whole learning process. It illustrates the importance of personal production, creative activity, the role of self-assessment, promotion of change and reflection "meta" learning how to learn. It is a step of recontextualization in which the student builds something personal.

\section{TEACHERS’ ACTING PROFILES}

The educational relationship is a set of verbal and nonverbal characterizing the act of teaching. These exchanges are affected by teaching methods practiced by the teacher. DeLandsheere and Bayer have classified these exchanges in seven categories, called pedagogical functions that cover the key events of school life. Each educational function is characterized by a set of measurable actions which, once identified, resulting in their existence and sequencing the action plan of the teacher, his rational way to organize a practical rule of advance operations to accomplish. This awareness comes not only from theoretical knowledge but especially from the implementation of this knowledge in the field. 


\section{A. Pedagogical assessment}

The organizing function that sets the conditions and context in which the act of teaching-learning must be given. Imposition function is for the content of education or starting framework facilitating stimulation. The development function designed by educational and teaching techniques used by teachers to ensure the development of intellectual and psychomotor abilities of the student. The personalization function uses the previous knowledge and representations of student achievements, including his own difficulties. The function of positive and negative evaluation that informs students of the quality of its performance, positive and negative affectivity related to the student personality, eventually, the realization function that characterizes the teaching aids and technical visual, auditory used to channel information to the student to achieve an optimal acquisition of knowledge.

Each measure of verbal and nonverbal teacher's act must be categorized to the proper pedagogical function; the corresponding time periods must be measured during the course of the activity. An acquisition tool is designed, offering a friendly interface formed by the grid functions and its criteria. A simple click on each criterion detected in the act of teaching that the algorithm accounts for the periods corresponding acts, it collects and makes the combined category. The data collected is stored in a spreadsheet. This algorithm has been validated in advance before its systematic use to ensure its adequacy and accuracy is sufficient.

As a first approach, we opted for the visualization of statistical results in the form of histograms in a plane with two axes representing teaching functions on the horizontal axis and the cumulative final frequency on the vertical axis. This has an

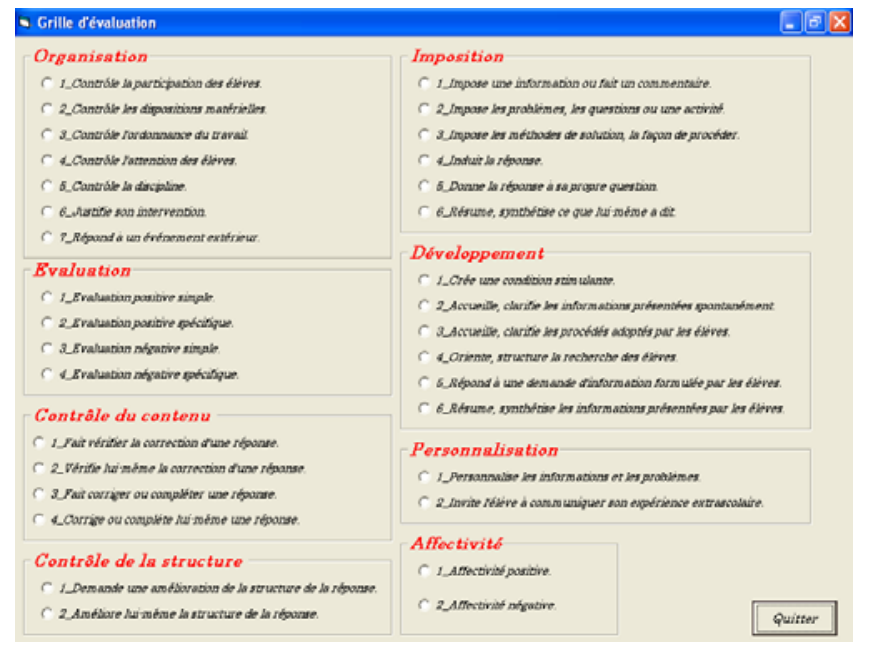

Figure 3

effect not only on visualization of comparative quantities frequencies educational functions between them, but especially between the same functions measured at successive visits.

\section{B. Behavioral assessment}

Since the teacher is not perceived by its students solely on the cognitive but also in terms of personality: "we teach what we know with what we are", it would be appropriate to conduct assessment of attitudes, behaviors and methods of teaching, especially that within his personality, the same order is preserved if we go from what is the most spontaneous to what is more built as finalized and The more organized.

Behavior estimation scale

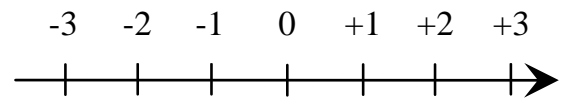

TABLE I

\begin{tabular}{|c|c|c|}
\hline Distant & \multirow{8}{*}{$\begin{array}{c}\text { Behavior } \\
\text { estimation scale }\end{array}$} & Available \\
\hline Narrow-minded & & Comprehensible \\
\hline Hard & & Kind \\
\hline Dull & & Stimulating \\
\hline Stereotype & & Original \\
\hline Indecisive & & Confident \\
\hline Excitable & & Sedate \\
\hline Disorganized & & Methodical \\
\hline
\end{tabular}

\section{Teaching methods}

As teachers, the more we know about how our students think and learn, the more successful we will be at helping them realize their educational goals. Teachers are learners too, and we often use teaching methods in our classrooms that complement our own personal learning styles. Our teaching styles may not be effective for our students, who may have learning styles that are very different from our own. There are many ways to assess learning style preferences for our students ( and for ourselves): most of these methods rely on the use of diagnostic learning style preference "tests" that are based on one of the learning style models ( Myers-Briggs Type Indicator, Kolb’s Learning Style Model, Herrmann Brain Dominance Instrument, Felder-Silverman Learning Style Model).

A teaching method describes the pedagogical means adopted by the teacher to enhance learning and achieve its educational objective. The teacher values over a given time one method than another, at the discretion of the teacher is often a matter of circumstances. To facilitating learning and mediation of knowledge, it is important to review regularly the method of teaching. It is customary to distinguish five teaching methods: expositive, demonstrative, interrogative, discovery and experiential. They can be practiced in a teaching sequence or individually or in small or large groups with the mediation of educational tools.

With transmissive method, the teacher has skills in a structured content and transmit knowledge in the form of presentation, the lecture that leaves little place for interactivity with the learner. In the didactic triangle, this corresponds to the relationship teachers - knowledge where the teacher is an expert of the content, a keeper of truth, which transmits information unambiguously.

The teacher determines a path teaching in demonstrative method: he shows, he makes doing and then make the student to formalize in order to assess the degree of understanding. This method is often used to make the student acquires skills through simple imitation. 
Within interrogative method, the student is recognized as having elements of knowledge or representation of content acquisition. Using appropriate questioning, the teacher allows students to construct knowledge by himself or to make connections and make sense of these disparate elements. The student or student group is encouraged to formulate what he knows, what he thinks, what he represents

The teacher creates a scenario, when using an active method, with educational materials that can use trials and errors to learn. He mobilizes the experience of the student or of a group of students to assess the situation and solve the problem with their means. Intracognitif and co-development work between peers is promoted.

Many disciplines or knowledge can be taught but learned by doing with people who can do such as, medicine or art. This knowledge is gained by the student in and by the action in a real project. The teacher encourages the formalization of knowledge by the student who is the real producer of knowledge sharing and re-elaborates it with others. This is what is called experiential method.

\section{STUDENT'S LEARNING STYLES}

For any academic training, the learner is implicit target, around which is built a huge process to make him, explicitly, the main actor. It must therefore be identified by our system on different plans and different levels. Beginning with a thorough study of its intelligence and its many facets that make up the dynamics of cognitive development, types of interactions with his teachers, peers, the learning content, technology media in use, and its environment. An environment that must demonstrate its social presence is the result, among other things, of its interactivity and its affectivity. His cognitive presence outcome of the accommodation of its prerequisites with new knowledge and assimilation. Self-regulation and self-evaluation are also identifiable skills in the learner through various indicators which converge, too, with those of his learning style. We consider motivation and attention of the learner in order to be able to "detect" at will during the teaching learning sequence through their determinants in order to maintain an optimal level and maintain it.

Learners are intrinsically different and have different preferred learning styles. Learning styles indicate the way people prefer to "receive" information, they address the learner's preferences for the learning environment and his modality preference. Mc Carthy identifies within his research four student's learning styles. First, innovative learners who are interested in personal meaning of knowledge, they need to have reasons for learning. Reasons that connect new information with personal experience and establish that information's usefulness in daily life. Second, analytic learners who are interested in acquiring facts in order to deepen their understanding of concepts and processes. They learn effectively from lectures and they enjoy independent research, analysis of data, hearing what "the expert" has to say. Third, common sense learners, they are essentially interested in how things work, they want to "get in and try it", they learn effectively with concrete experiential learning activities using manipulative, hands-on tasks, Kinaesthetic experience and so on. Finally, dynamic learners who are interested in self directed discovery, they enjoy simulations, role play and games.

The modalities of those learning styles are subdivided into four categories. Visual verbal learning style in which information is presented visually in a written language format. Visual non verbal style, information is presented visually and in a picture or design format. Students with this modality of learning, benefit from teachers who use visual aids such as film, video, maps and charts. They may have an artistic side that enjoys activities having to do with visual art and design. Students with tactile kinaesthetic learning style learn best when physically engaged in a "hands on" activity. They benefit from laboratory setting where they can manipulate materials to learn new information. Learners with auditory verbal learning style learn best when information is presented auditory in an oral language format, so they interact with others in a listening speaking exchange. They benefit from listening to lecture and participating in group discussions. When trying to remember something, they can often "hear" the way someone told them the information, or the way they previously repeated it loud.

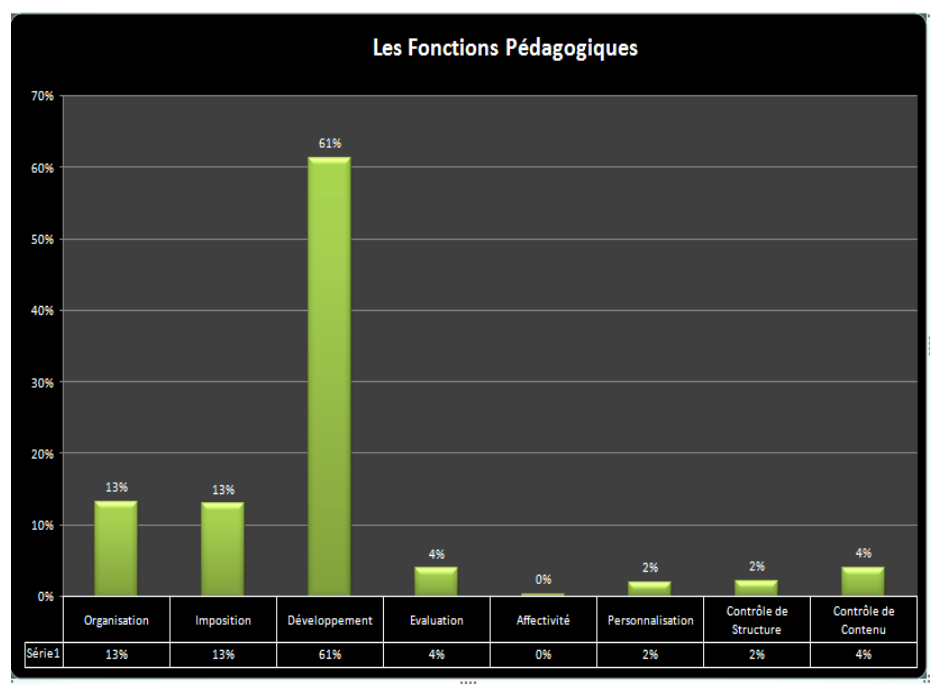

Figure 4

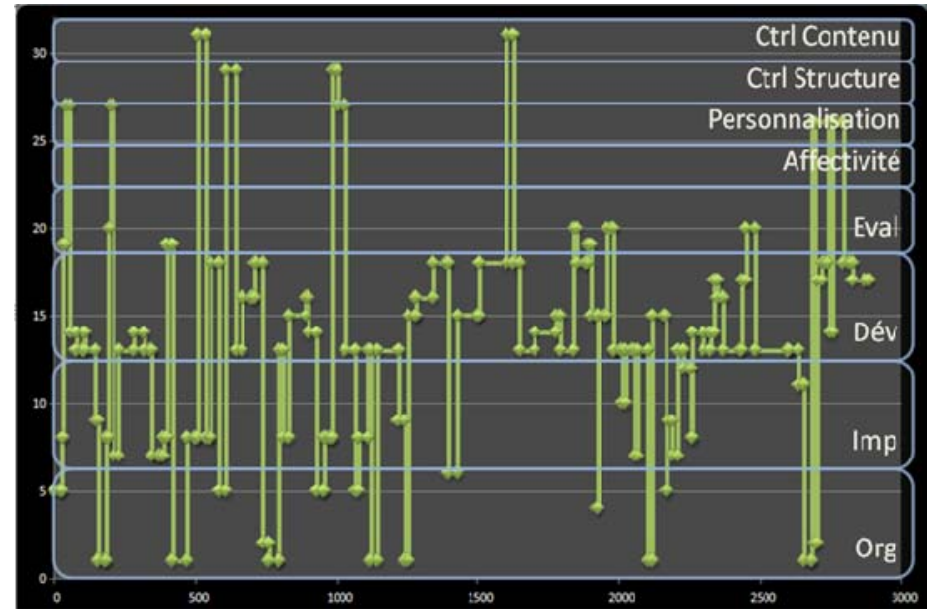

Figure 5 


\section{RESUlts}

The evolution of the teacher's practices in class will decrease school failures enormously and will support a relevant educational insertion. This evolution is the result of the reflexive practices that the professor starts as soon as he has between his hands the static recordings of his professional practices in the forms of histograms. These histograms illustrate the cumulated rates of the teaching pedagogical functions. The teacher can read measurements of his acts and discriminate those which are harmful with any active way. A way with it the teacher plays the part of an organizer, facilitating the access to knowledge which is built by the student in an autonomous motivating style. The teacher can also read the evolution of his practices during the time of the course: it is the dynamic aspect of the recording.

\section{CONCLUSION}

Teachers have experienced a major interest to the various statistics generated at the point where they cheered as soon as the course ended and they often inquire about the meanings of educational functions whose performance is lacking. There is even that in many cases, following a second visit, the development function becomes more dominant than that of imposition. We also note that personalization appears, negative affectivity is substituted with positive one. In some cases, especially for older teachers, they find it difficult to assign the practice of imposition in favor of one that is developed. Despite this, one finds that the development practices evolve without the knowledge of the stagnation of imposition. All teachers visited, old or young, have been manifest in their professional practice developments relating to acts that promote centering on the student in performing their function of teaching learning. Changing teaching practices in the direction of better focus on the pupil, following the identification of their past practices by the evaluation grid used.

One of the challenges which threaten more the educational world and especially the secondary and academic levels is the uninspired pupils. They do not take any interest in what occurs in class and they give up every attempt of fixing to the course of their learning dice the slightest difficulty. The situation is still worsened with the feeling of routine which invades the professor at the time of his practices in class. In this work method and with the instructions of assistance which the expert system generates, the professor and the pupil are in harmony in the classroom. The teacher recognizes his pupil well by adapting his manners to him; the pupil is suitably framed with the feeling of being the Master of the situation who can construct in an autonomous way his knowledge.

\section{REFERENCES}

[1] Ph. Perrenoud, (1991) "Choisir et former des cadres pour un système éducatif plus décentralisé et plus participatif” Genève, Faculté de psychologie et des sciences de l'éducation, Vol. $11 n^{\circ} 4$, pages 3-7.

[2] Ph. Perrenoud, (1996) "L'évaluation des enseignants : entre une impossible obligation de résultats et une stérile obligation de procédure”, L’Educateur n¹0, pages 24-30.
[3] M. Mazeran, (1989) “Gestion et évaluation des personnels enseignants”, La Revue des Echanges (AFIDES), Vol. 12 n¹, pages 2-13

[4] M. Tardif, C. Lessard (1999) "le travail enseignant au quotidien. Expériences, interactions humaines et dilemmes professionnels", Québec, Presses de l’université de Laval et Bruxelles De Boeck.

[5] J.M De Ketele (1986), "L'évaluation : approche déscriptive ou prescriptive ?", De Boeck, Bruxelles.

[6] Ch. Hadji, "L’évaluation, régles du jeu", Paris, ESF éditeur, pages 71-74

[7] M. Altet (1994), "La formation professionnelle des enseignants", Paris, PUF.

[8] M. Postic (1992), "Observation et formation des enseignants", Paris, Presses universitaires de France.

[9] M. Postic et J.M. De Ketele (1988), “Observer des situations éducatives”, Paris, PUF.

[10] TECSULT (2003), "L’analyse des pratiques professionnelles”.

[11] L. Schnackenberg, "Introduction to Educationnal Computing."

[12] R. Baehrel and W. Henderson, "Laissons les apprendre activement en toute sérénité".

[13] Thietart A et coll (1999) méthodes de recherche en management, Dunod, MCG 335

[14] De Singly F (1992), l'enquête et ses méthodes: le questionnaire, Nathan, GDP 156

[15] Ryan, R. M., \& Deci, E. L. (2000). Self-determination theory and the facilitation of intrinsic motivation, social development, and well-being. American Psychologist, 55, 68-78.

[16] Reeve, J., Nix, G., \& Hamm, D. (2003). The experience of selfdetermination in intrinsic motivation and the conundrum of choice. Journal of Educational Psychology, 95, 375-392.

[17] Deci, E. L., La Guardia, J. G., Moller, A. C., Scheiner, M. J., \& Ryan, R. M. (2006).

[18] Roth, G., Assor, A., Kanat-Maymon, Y., \& Kaplan, H. (2007). Autonomous motivation for teaching: How self-determined teaching may lead to self-determined learning. Journal of Educational Psychology, 99, 761-774.

[19] Reeve, J., \& Tseng, C.-M. (2009). Adding voice as a fourth component of student engagement during learning activities. Manuscript submitted for publication. 